\title{
Sensory assessment of meshed skin grafts over free gracilis muscle flaps without nerve coaptation for lower extremity reconstruction
}

\author{
Mathias Tremp ${ }^{1 *}$, Natascha J. Waldkircher ${ }^{1 *}$, Wenjin Wang ${ }^{2}$, Carlo M. Oranges ${ }^{1}$, \\ Pietro G. di Summa ${ }^{3}$, Yixin Zhang ${ }^{2}$, Wei Wang ${ }^{2}$, Dirk J. Schaefer ${ }^{1}$, Daniel F. Kalbermatten ${ }^{1}$ \\ ${ }^{1}$ Department of Plastic, Reconstructive, Aesthetic and Hand Surgery, University Hospital Basel, Basel, Switzerland; ${ }^{2}$ Department of Plastic \\ and Reconstructive Surgery, Shanghai Ninth People's Hospital, Shanghai Jiaotong University School of Medicine, Shanghai, China; ${ }^{3}$ Division \\ of Plastic, Reconstructive and Aesthetic Surgery, University Hospital of Lausanne (CHUV), Lausanne, Switzerland
}

\begin{abstract}
Background Little is known about the sensate recovery of skin grafts over free non-neurotized muscle flaps. The aim of this study was to evaluate the sensitivity of free gracilis muscle flaps and meshed skin grafts without nerve coaptation.

Methods Thirteen consecutive patients with a median age of 55 years (range, 21-70 years) who underwent lower extremity reconstruction between September 2014 and October 2016 were included. Complications, flap contour, skin perception, and sensate recovery were assessed.

Results All flaps survived completely. In one patient, wound dehiscence and infection occurred 1 month after surgery. After a median follow-up of 14 months (range, 10-51 months), a satisfactory contour and skin perception were achieved. The Semmes-Weinstein (SW) monofilament test $(154.8 \pm 22 \mathrm{~g})$ and static two-point discrimination (2-PD) $(12.6 \pm 0.7 \mathrm{~mm})$ showed intermediate recovery compared to the surrounding site ( $41 \%$ and $76 \%$, respectively). There was an intermediate correlation between flap size and sensate recovery (2-PD: $r=0.27$, $P=0.36$; SW test: $r=0.45, P=0.12$ ). Vibration sensation recovered to $60 \%$, whereas thermal sensation remained poor $\left(19 \%\right.$ at $5^{\circ} \mathrm{C}$ and $25 \%$ at $\left.25^{\circ} \mathrm{C}\right)$.
\end{abstract}

Conclusions Finer sensation could be partially restored. However, thermal sensation remained poor.

Keywords Muscle flap / Nerve regeneration / Patient outcome assessment / Reconstruction / Sensation

\section{Correspondence:}

Daniel F. Kalbermatten

Department of Plastic, Reconstructive, Aesthetic and Hand Surgery, University Hospital Basel, Spitalstrasse 21, Basel 4031, Switzerland

Tel: +41-61-265-25-25

Fax: +41-61-265-73-01

E-mail: daniel.kalbermatten@usb.ch

${ }^{*}$ The two authors contributed equally to this work.

This study was supported by the SinoSwiss Science and Technology Cooperation (Project No.: EG 07032014), and the Swiss Society of Plastic, Reconstructive and Aesthetic Surgery.

This article was presented at the 53rd Annual Meeting of the Swiss Society of Plastic, Reconstructive and Aesthetic Surgery, on September 1-2, 2017, in St. Moritz, Switzerland.

The authors would like to thank Selina Ackermann (Department of Surgery, University Hospital Basel, Switzerland) for organizational work and revising our manuscript.

Received: April 19, $2019 \bullet$ Revised: August 10, $2019 \bullet$ Accepted: August 23, 2019

pISSN: 2234-6163・ elSSN: 2234-6171・ https://doi.org/10.5999/aps.2019.00584• Arch Plast Surg 2021;48:224-230

\section{INTRODUCTION}

Connecting not only the vascular supply, but also sensitive nerves, represents an appealing option in free tissue transfer [1]. However, in certain cases, such as breast or extremity reconstruction, the feasibility of coaptation of sensory nerves of the

Copyright $\odot 2021$ The Korean Society of Plastic and Reconstructive Surgeons

This is an Open Access article distributed under the terms of the Creative Commons Attribution Non-Commercial License (https://creativecommons.org/

licenses/by-nc/4.0/) which permits unrestricted non-commercial use, distribution, and reproduction in any medium, provided the original work is properly cited. I www.e-aps.org 
flaps remains questionable [1].

Although the coaptation of sensory nerves in soft-tissue reconstruction with free flaps is frequently conducted [2-6], spontaneous return of sensation without sensory nerve coaptation has been reported [7]. Non-sensate free muscle flaps (e.g., the gracilis muscle flap, latissimus dorsi muscle flap, or rectus abdominis muscle flap [8]) with free skin grafts represent an attractive alternative, and are common procedures in reconstructive microsurgery [9]. Excellent rates of spontaneous reinnervation in skin grafts over free muscle flaps that have been sensory-neurotized after sensory nerve-to-motor nerve transfer were recently found in both human and animal studies [10]. Restoration of the sensitivity of skin that has been grafted onto the transferred muscle is of vital importance [9], but it has been postulated that free muscle flaps are fully denervated tissue, and that satisfactory innervation of the overlying skin graft cannot be expected. Reinnervation occurs mostly through the surrounding tissue if no nerve branch is sensitized, and it may take a long time to develop. Therefore, functional sensation is hardly restored, nor is adequate tactile sensation or two-point discrimination (2-PD) achieved [11].

The aim of this study was to evaluate sensitivity in skin grafts over free, non-neurotized gracilis muscle flaps for lower extremity reconstruction.

\section{METHODS}

\section{Patients}

Between September 2014 and October 2016, a total of 13 consecutive patients (nine male and four female patients; median age, 55 years; range, $21-70$ years) after reconstruction of the lower extremity in non-weight-bearing areas using a free, nonneurotized gracilis flap and meshed skin graft of $0.2-\mathrm{mm}$ thickness were included. Five of these patients had undergone previous surgery on the affected limb. There were no exclusion criteria in this study. Defect sizes ranged from 5 to $27 \mathrm{~cm}$ (length) $\times 4$ to $14 \mathrm{~cm}$ (width), with median dimensions of $16 \mathrm{~cm} \times 6 \mathrm{~cm}$. All operations were performed by the senior author (DFK), and the technique of the secret scar-free gracilis flap was applied using a horizontal thigh lift approach [12]. Sensate recovery was prospectively assessed at the final follow-up, whereas flap size, co-morbidities, etiology, complications, and baseline patient characteristics were assessed retrospectively. Written informed consent was obtained from all patients, and the guidelines of the Declaration of Helsinki were followed. Ethics board approval was otherwise not obtained because all other elements of the study fell within the routine clinical patient workup, as previously described [13].
The following postoperative complications were evaluated: ulcerations, hyperkeratosis, wound breakdown, lacerations, hematoma, and flap necrosis. Flap contour evaluation was also performed, whereby patients and one independent assessor classified the integration in terms of the superficial two-dimensional aspect as "good" or "poor" [6]. Moreover, patients were asked if they sensed the skin of the flap as abnormal or normal, and whether the selection of footwear was problematic.

\section{Surgical technique}

The gracilis flap was divided into four equal parts with a circle in the middle of approximately $2 \mathrm{~cm}$ diameter (zone $\mathrm{Z}$ ). Zone $\mathrm{Z}$ and zone 1 represent the entry point of the pedicle into the gracilis flap, zones 2 and 3 are lateral to zone $Z$, and zone 4 is opposite from the pedicle (Fig. 1). One independent assessor who was not part of the surgical team performed all evaluations. Sensate recovery was evaluated using the Semmes-Weinstein (SW) monofilament examination (Aesthesio; Danmic Global LLC, San Jose, CA, USA), static 2-PD, vibration sensation (tuning fork of $432 \mathrm{~Hz}$ ), and thermal sensation (metal rods at $5^{\circ} \mathrm{C}$ and $25^{\circ} \mathrm{C}$ ), and the results were compared with the corresponding surrounding tissue of the evaluated flap zone apart from the wound edge (zones 1'-4') (Fig. 1). Vibration, thermal sensation, the SW monofilament test, and 2-PD are established assessment tools for sensate recovery and tactile gnosis [1].

The 2-PD and the SW monofilament test results were classified into three groups (good, intermediate, and poor) [14]:

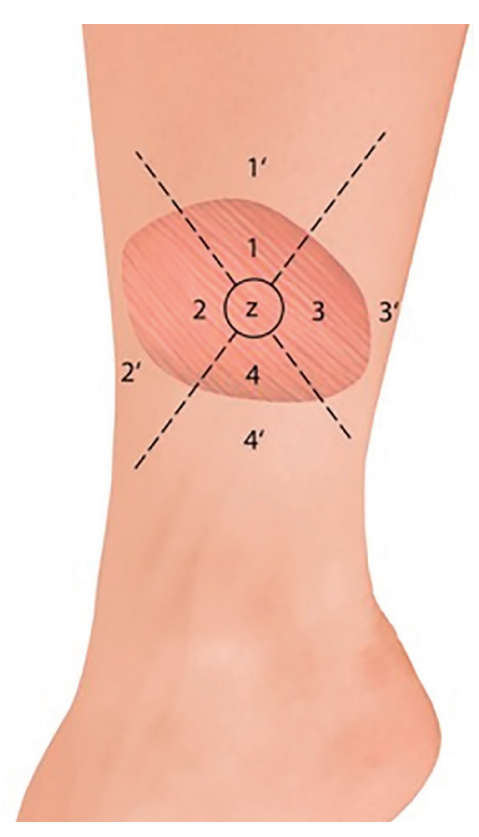

Fig. 1. Diagram of the muscle flap and zones. Diagram showing the muscle flap divided into five zones, with the corresponding surrounding zones. 
good indicates that the sensory test values regained a level of greater than $80 \%$ compared with the surrounding area; intermediate restoration signifies that the sensory test values regained a level between $20 \%$ and $80 \%$; and poor sensate recovery means that the values regained a level below $20 \%$. Moreover, the correlation between flap size $\left(\mathrm{cm}^{2}\right)$ and corresponding sensate recovery (mean SW monofilament and 2-PD measurements from each flap [zones 1-4 and zone Z]) was evaluated.

\section{Statistical analysis}

The values are shown as the median with range or mean and standard deviation or standard error of mean where appropriate. Patients' responses to SW monofilament testing and 2-PD were compared between the zones of the muscle flap and corresponding healthy sites using one-way analysis of variance with the corresponding Tukey post-hoc test. Statistical significance was determined by a value of $\mathrm{P} \leq 0.05$. The correlation between flap size $\left(\mathrm{cm}^{2}\right)$ and sensate recovery was calculated at a $5 \%$ level using the Pearson correlation coefficient. All statistical tests were performed at a significance level of $\alpha=0.05$ using GraphPad Prism version 5.00 for Windows (GraphPad Software, San Diego, CA, USA).

\section{RESULTS}

The indications for the free gracilis flap, defect size, localization, co-morbidities, and outcomes are summarized in Table 1. In all cases, the volume of the muscle flaps (median flap weight, $114 \mathrm{~g}$; range, 32-225 g) was sufficient to cover the defects (Fig. 2). In six patients, the gracilis muscle flap was trimmed accurately to fit precisely into the recipient site (median resected muscle weight, $33 \mathrm{~g}$; range, 5-90 g). All flaps survived completely without any marginal necrosis or hematoma, and the skin graft take was $90 \%-100 \%$ within 2 weeks in all cases (no grafts were lost to infection). In one patient, wound dehiscence and infection that required revision occurred 1 month after surgery. Three patients presented with ulcerations or hyperkeratosis over the ankle at the final follow-up. Satisfactory contours were achieved for both the patient and the surgeon ( 11 of 13 patients and 10 of 13 patients, respectively). Seven patients indicated that they were not restricted in the choice of footwear. After a median follow-up time of 14 months (range, 10-51 months), eight of the 13 patients reported normal skin perception. Overall, the SW monofilament test and static 2-PD showed intermediate recovery compared with the corresponding healthy site $(41 \%$ and $76 \%$, respectively) (Fig. 3). The SW monofilament measurements only showed a significant difference compared with the corresponding healthy site in zone $1(201 \pm 42 \mathrm{~g}$ vs. $24.24 \pm 23$ g, $\mathrm{P}<0.05$ ) (Fig. 4). The highest values were found for the middle of the flap (zone Z, $300 \mathrm{~g} \pm 0$ ). The 2-PD measurements revealed no significant differences between the flap zones and the corresponding sites, with the lowest pressure sensation in the

Table 1. Patient demographics, etiology, co-morbidities, complications, and outcomes

\begin{tabular}{|c|c|c|c|c|c|c|c|c|c|c|c|c|}
\hline \multirow{2}{*}{$\begin{array}{l}\text { Age } \\
\text { (yr)/ } \\
\text { sex }\end{array}$} & \multirow{2}{*}{$\begin{array}{c}\mathrm{BMl} \\
\left(\mathrm{kg} / \mathrm{m}^{2}\right)\end{array}$} & \multirow{2}{*}{$\begin{array}{c}\text { Defect } \\
\text { Iocalization }\end{array}$} & \multirow{2}{*}{ Etiology } & \multirow{2}{*}{ Co-morbidities } & \multirow{2}{*}{$\begin{array}{l}\text { Defect size, } \\
\text { length } \times \\
\text { width }(\mathrm{cm})\end{array}$} & \multicolumn{2}{|c|}{ Flap contour } & \multirow{2}{*}{$\begin{array}{c}\text { Skin } \\
\text { perception }\end{array}$} & \multirow{2}{*}{$\begin{array}{l}\text { 2-PD } \\
(\mathrm{mm})\end{array}$} & \multirow{2}{*}{$\begin{array}{l}\text { SW } \\
(\mathrm{g})\end{array}$} & \multirow{2}{*}{ Complications } & \multirow{2}{*}{$\begin{array}{l}\text { Follow- } \\
\text { up } \\
\text { (mon) }\end{array}$} \\
\hline & & & & & & Assessor & Patient & & & & & \\
\hline 69/M & 29.05 & Ankle & Infection & None & $9 \times 11$ & Good & Good & Normal & $11.8(9-15)$ & $2.8(2-4)$ & None & 14 \\
\hline $63 / F$ & 31.16 & Lower leg & Trauma & None & $10 \times 6$ & Good & Good & Abnormal & $10.3(5-15)$ & $61.6(0.07-300)$ & None & 14 \\
\hline $21 / F$ & 21.51 & Ankle & Trauma & None & $18 \times 6$ & Good & Good & Normal & $13(11-15)$ & $182(4-300)$ & None & 12 \\
\hline $57 / F$ & 36.33 & Ankle & Trauma & Obesity & $13 \times 8$ & Poor & Poor & Abnormal & $15(15-15)$ & $122(4-300)$ & None & 28 \\
\hline 42/M & 29.43 & Lower leg & Trauma & Smoking & $18.5 \times 4$ & Poor & Poor & Abnormal & $13(11-15)$ & $182(4-300)$ & None & 23 \\
\hline 70/M & 38.51 & Lower leg & Trauma & $\begin{array}{l}\text { Hypertension, obesity, } \\
\text { hypercholesterolemia }\end{array}$ & $17 \times 14$ & Good & Good & Normal & $15(15-15)$ & $241(4-300)$ & None & 42 \\
\hline $31 / F$ & 28.60 & Ankle & Infection & None & $5 \times 5$ & Good & Good & Normal & $15(15-15)$ & $300(300-300)$ & None & 51 \\
\hline $61 / \mathrm{M}$ & 27.33 & Ankle & Trauma & Diabetes & $16 \times 5$ & Poor & Good & Normal & $15(15-15)$ & $241(4-300)$ & None & 10 \\
\hline 33/M & 24.90 & Ankle & Trauma & None & $16 \times 4$ & Good & Good & Abnormal & $14.5(13-15)$ & $122(2-300)$ & Ulceration & 10 \\
\hline 33/M & 25.64 & Ankle & Trauma & Smoking & $27 \times 11$ & Good & Good & Normal & 15 (15-15) & $300(300-300)$ & Ulceration & 43 \\
\hline $66 / \mathrm{M}$ & 35.35 & Ankle & Trauma & $\begin{array}{l}\text { Hypertension, smoking, } \\
\text { obesity, peripheral } \\
\text { vascular disease }\end{array}$ & $17 \times 12$ & Good & Good & Abnormal & $15(15-15)$ & $300(300-300)$ & None & 12 \\
\hline $41 / \mathrm{M}$ & 22.22 & Ankle & Trauma & $\begin{array}{l}\text { Smoking, hepatitis B } \\
\text { and C }\end{array}$ & $11 \times 8$ & Good & Good & Normal & $15(15-15)$ & $122(4-300)$ & Hyperkeratosis & 11 \\
\hline $55 / \mathrm{M}$ & 27.58 & Ankle & Infection & Smoking & $8 \times 5$ & Good & Good & Normal & $15(15-15)$ & $182(4-300)$ & $\begin{array}{l}\text { Wound } \\
\text { dehiscence, } \\
\text { infection }\end{array}$ & 12 \\
\hline
\end{tabular}

Values are presented as mean (range).

BMI, body mass index; 2-PD, 2-point discrimination; SW, Semmes-Weinstein monofilament test; M, male; F, female. 

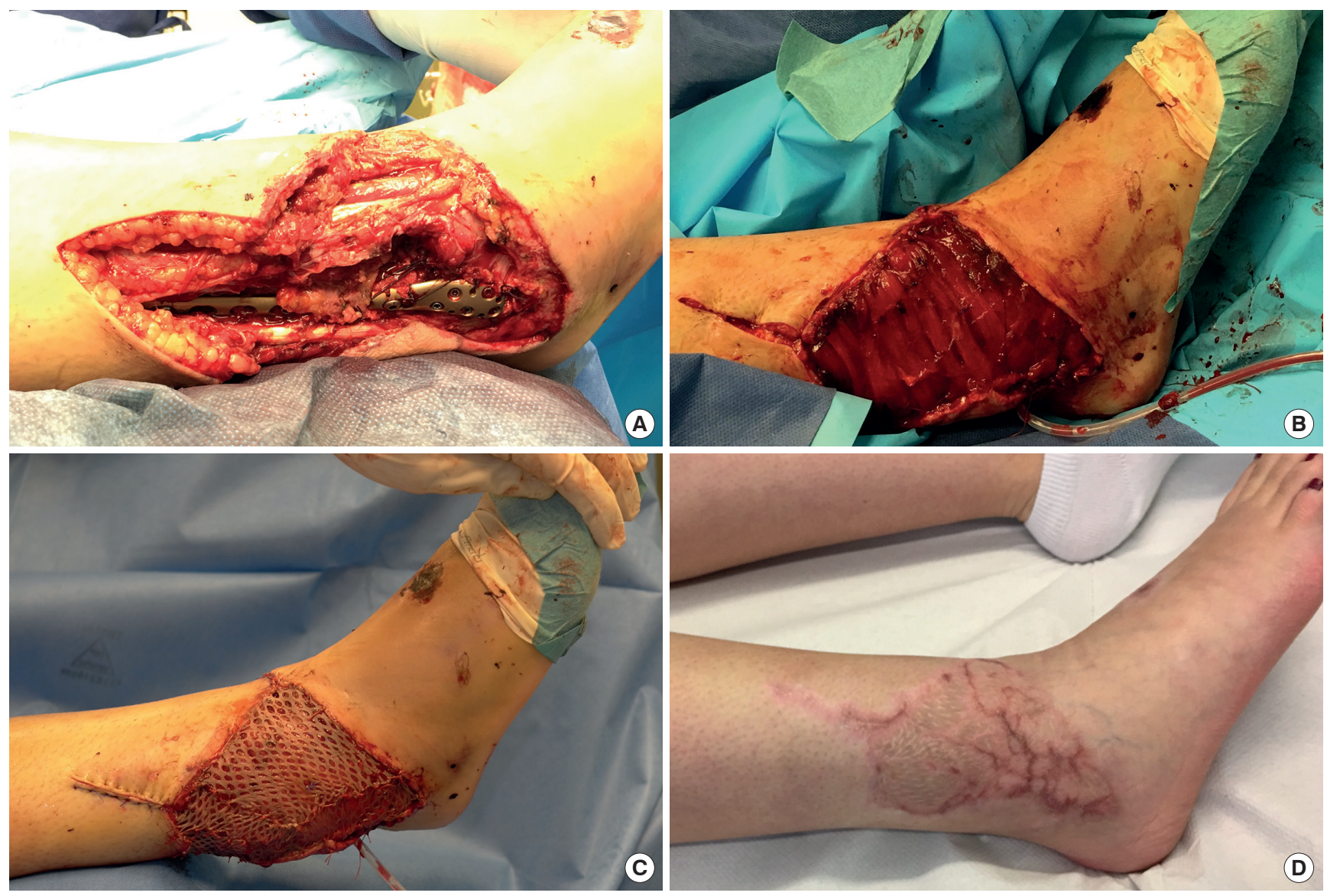

Fig. 2. A case of lower extremity reconstruction. (A) Representative case of a 21-year-old female patient with a compound lower limb fracture and soft-tissue damage (size of defect, $18 \times 6 \mathrm{~cm}$ ). ( $(\mathrm{B}, \mathrm{C})$ Defect reconstruction was performed with a microvascular, non-neurotized gracilis flap (pedicle length, $8 \mathrm{~cm}$ ) harvested from the opposite site and a split-thickness skin graft of $0.2-\mathrm{mm}$ thickness. The anterior tibial artery was selected for end-to-end anastomosis with two concomitant veins. (D) After a follow-up of 6 months, stable and complete soft-tissue coverage was achieved with a satisfactory contour. The patient indicated normal skin perception with an overall Semmes-Weinstein measurement of $182 \mathrm{~g}$ (range, 4-300 g), a static two-point discrimination of $13 \mathrm{~mm}$ (range, 11-15 mm), perceived vibration, and a lower perception for thermal sensation.

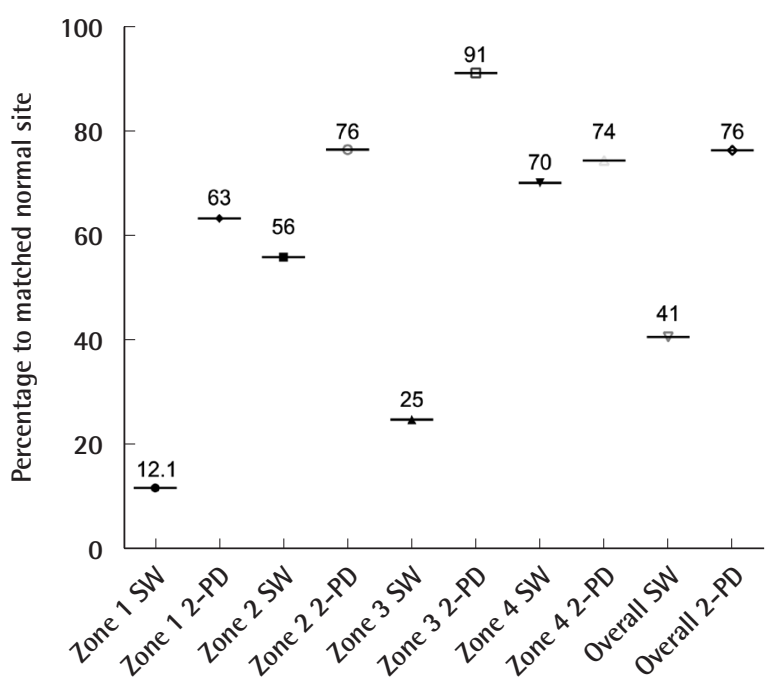

Fig. 3. Pressure monofilament test and static 2-PD. The overall cutaneous pressure (SW monofilament test and static 2-PD) between the flap zones and the corresponding site is shown (\%). SW, SemmesWeinstein; 2-PD, 2-point discrimination.

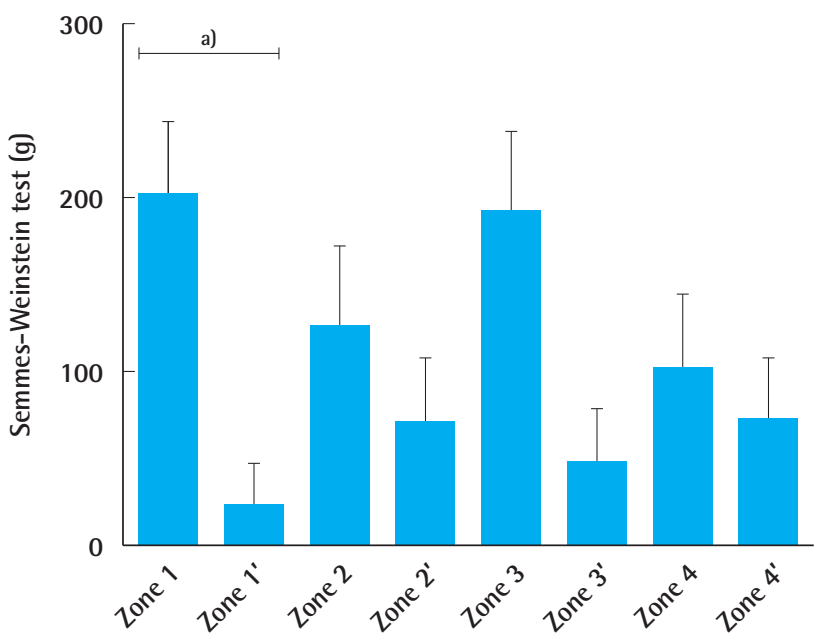

Fig. 4. Average cutaneous pressure threshold across the zones. The overall average cutaneous pressure (Semmes-Weinstein) threshold between the various flap zones and corresponding sites is shown. Data are expressed as mean \pm standard error of the mean. ${ }^{\text {al }} \mathrm{P}<0.05$. 


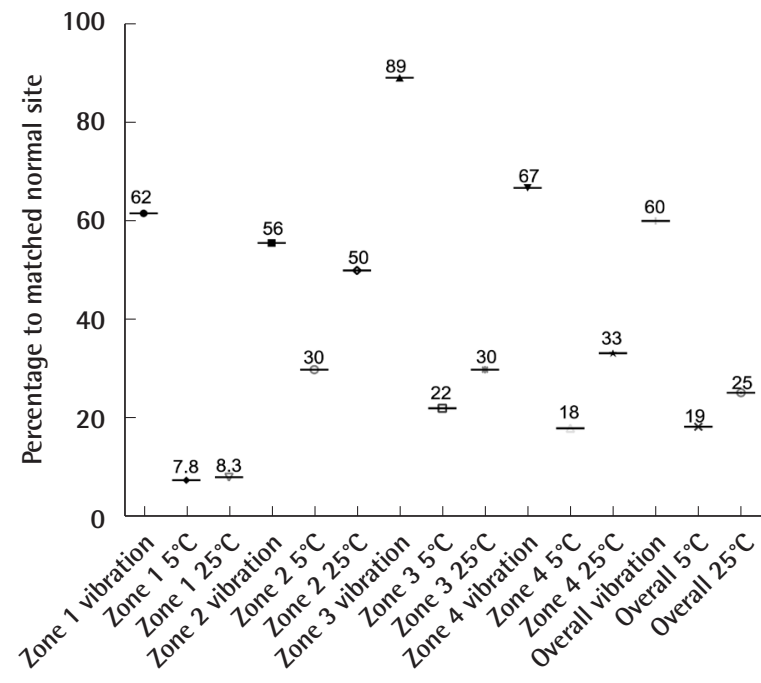

Fig. 5. Painful protective sensations across the flap zones. Painful protective sensations (temperature and vibration) were compared between the flap zones and the corresponding sites (\%). Thermal sensation was restored to a lesser extent than vibration.

middle. Five patients had previous surgery on the affected limb, but they showed similar sensory recovery compared with the remaining patients $(14.7 \mathrm{~mm}$ vs. $13.4 \mathrm{~mm}$ for 2-PD measurements and $201.3 \mathrm{~g}$ vs. $157 \mathrm{~g}$ for the SW monofilament test, similar vibration and thermal sensation). We found an intermediate correlation between flap size and sensate recovery $(r=0.27$, $\mathrm{P}=0.36$ for the mean 2-PD measurements; $\mathrm{r}=0.45, \mathrm{P}=0.12$ for the mean SW monofilament measurements). While overall vibration sensation was restored to a similar extent $(60 \%$ compared with the surrounding tissue), overall thermal sensation remained poor $\left(19 \%\right.$ at $5^{\circ} \mathrm{C}$ and $25 \%$ at $25^{\circ} \mathrm{C}$, respectively) (Fig. 5). In the middle of the flap (zone $\mathrm{Z}$ ), only three patients were able to feel vibration and thermal sensation (two patients felt $5^{\circ} \mathrm{C}$ and one patient felt $25^{\circ} \mathrm{C}$ ).

\section{DISCUSSION}

One of the ultimate goals of lower extremity reconstruction is a cosmetically pleasing contour, with preserved sensation where possible [1]. The method of reconstruction should be chosen according to the local requirements and the location of the defect [4]. Different algorithms have been suggested for the selection of the ideal flap for lower extremity defect reconstruction. In elderly patients, nerve regeneration after nerve coaptation is limited due to small vessel disease, age, or polyneuropathy in patients with diabetes, for example [1]. Therefore, potentially, young patients can receive free fasciocutaneous perforator flaps or muscle flaps for three-dimensional defect reconstruction, sensate if possible, whereas elderly patients benefit more from non-sensate gracilis muscle flaps [1].

Nevertheless, we noticed hyperkeratosis and ulceration in three patients over the ankle, which might be a potential drawback of free muscle flaps with skin grafts over friction zones [15]. The lack of sufficient superficial cutaneous sensation might be a significant contributor to ulceration, even in cases of deep pressure sensation [15]. Eventually, skin grafted muscular free flaps over friction zones may need to be replaced with sensate fasciocutaneous flaps [15]. A further potential limitation of muscle flaps might be long-term soft-tissue instability, especially in weight-bearing areas, compared to fasciocutaneous flaps $[16,17]$.

It has been reported that free muscle flaps with sensory or motor coaptation can regain sensitivity [18]. To date, the possibility of sensory restoration of grafted skin has been proven in animal models on a trimmed gracilis muscle surface after sensory nerve-to-motor nerve transfer [9]. Moreover, Gordon et al. [19] and Chang et al. [18] attempted to achieve sensory restoration in a muscle flap with skin grafts using a local sensory nerve that was coapted to the motor nerve for heel and foot sole restoration; however, assessing the critical role of the sensory reinnervated skin graft on a muscle flap proved difficult.

Our results indicate that spontaneous reinnervation of skin grafts on free, non-neurotized muscle flaps is possible. Furthermore, these findings contradict the pre-existing dogma that free non-neurotized muscle flaps are denervated tissue. We observed better recovery of sensory innervation in the peripheral region of skin grafts, confirming the regeneration pattern from the skin margins of the flap to its center. However, although $60 \%$ of vibration sensation was recovered (as compared with the surrounding tissue), thermal sensation recovery remained poor. Potentially, vibration may also be perceived through the surrounding tissue, especially in smaller flaps. Nevertheless, our findings might extend the existing principles of lower extremity reconstruction, especially in patients requiring minimal donor site morbidity, a hidden donor site scar, and solid anchorage without shearing forces [12].

Although our results indicate spontaneous and functional sensation of the skin graft on free, non-neurotized muscle flaps, the results are still inferior to those of sensate fasciocutaneous flaps, but apparently superior to those of non-sensate fasciocutaneous flaps. Still, a precise comparison with corresponding results for fasciocutaneous flaps in the existing literature is difficult, considering differences in procedures, flap volumes, and flap surfaces.

Innervation is restored in skin grafts by the regeneration of nerve endings from the edges of the defect and from the graft bed $[15,20]$. Therefore, an innervated bed is required to regain innervation [20]. Furthermore, skin grafts are mostly innervat- 
ed by unmyelinated fibers, which transmit perceptions of temperature, pain, and gross touch, whereas finer sensations (e.g., light touch, vibration, and the 2-PD examination) are transmitted by heavily myelinated fibers and specialized sensory receptors [15].

This might partially explain why finer sensations can be partially restored. However, protective qualities remained poor in our study.

The regeneration of autonomic fibers along the arterial pedicle and into a free flap is another potential mechanism of sensory reinnervation in non-neurotized free muscle flaps, which may explain the better SW outcomes in zone 1 [21]. Furthermore, the thickness of the skin graft might be of particular relevance. Full-thickness skin grafts contain target structures (e.g., hair follicles, erector pili muscles, and sweat glands), and can potentially regain reasonable autonomic innervation. Skin receptors in full-thickness skin grafts exert a chemical attraction for the axons of the regenerated nerve, a phenomenon known as neurotropism [22]. However, in split-thickness skin grafts, these structures are lacking, and full-thickness skin grafts might be superior to partial-thickness skin grafts [9].

Our study has limitations, such as a limited sample size with a relatively short follow-up period, a lack of homogeneity, and the omission of a formal control group for comparison of our results. In addition, while there are myriad choices of free muscle flaps, such as the latissimus dorsi muscle flap, the serratus anterior muscle flap, and the rectus abdominis muscle flap [8], we only evaluated the free gracilis flap with a meshed skin graft after lower extremity reconstruction. Therefore, prospective randomized controlled trials are needed, including measurements of painful protective sensations by two independent investigators and correction for covariates, to confirm our findings. Moreover, anatomical and histological studies are needed to assess the origin of the partial spontaneous return of sensitivity to skin grafts over muscle flaps.

\section{NOTES}

\section{Conflict of interest}

No potential conflict of interest relevant to this article was reported.

\section{Ethical approval}

The local ethical committee approved the study in accord with the ethical standards of the Helsinki Declaration of 1964 and its later amendments or comparable ethical standards (Ref.-Nr.: 2019-02153). Written informed consent was obtained.

\section{Patient consent}

The patient provided written informed consent for the publication and the use of her images.

\section{Author contribution}

Conceptualization: Tremp M, Waldkircher NJ, Kalbermatten DF, Zhang Y. Format analysis: Schaefer DJ, di Summa PG, Wang Wei, Wang Wenjin. Funding acquisition: Kalbermatten DF, Tremp M, Wang Wenjin. Methodology: Schaefer DJ, Kalbermatten DF, Zhang Y, Wang Wenjin. Project administration: Tremp M, Waldkircher NJ. Visualization: Schaefer DJ, Tremp M, Kalbermatten DF, Waldkircher NJ. Writing - original draft: Tremp M, Kalbermatten DF, di Summa PG. Writing - review \& editing: Tremp M, Waldkircher NJ, Oranges CM, di Summa PG. Approval of final manuscript: all authors.

\section{ORCID}

Mathias Tremp https://orcid.org/0000-0001-6593-9690

Wenjin Wang https://orcid.org/0000-0001-7303-1973

Carlo M. Oranges https://orcid.org/0000-0003-1735-5329

Pietro G. di Summa https://orcid.org/0000-0002-1431-4479

Yixin Zhang https://orcid.org/0000-0002-3240-6174

Wei Wang https://orcid.org/0000-0001-7558-4782

Daniel F. Kalbermatten

https://orcid.org/0000-0002-6626-1233

\section{REFERENCES}

1. Sinis N, Lamia A, Gudrun H, et al. Sensory reinnervation of free flaps in reconstruction of the breast and the upper and lower extremities. Neural Regen Res 2012;7:2279-85.

2. Yildirim S, Gideroglu K, Akoz T. Anterolateral thigh flap: ideal free flap choice for lower extremity soft-tissue reconstruction. J Reconstr Microsurg 2003;19:225-33.

3. Santanelli F, Tenna S, Pace A, et al. Free flap reconstruction of the sole of the foot with or without sensory nerve coaptation. Plast Reconstr Surg 2002;109:2314-22.

4. Kuran I, Turgut G, Bas L, et al. Comparison between sensitive and nonsensitive free flaps in reconstruction of the heel and plantar area. Plast Reconstr Surg 2000; 105:574-80.

5. Yamauchi T, Yajima H, Kizaki K, et al. Sensory reconstruction in sensate radial forearm flap transfer. J Reconstr Microsurg 2000;16:593-5.

6. Kalbermatten DF, Wettstein R, vonKanel O, et al. Sensate lateral arm flap for defects of the lower leg. Ann Plast Surg 2008; 61:40-6.

7. Tindholdt TT, Tonseth KA. Spontaneous reinnervation of deep inferior epigastric artery perforator flaps after second- 
ary breast reconstruction. Scand J Plast Reconstr Surg Hand Surg 2008;42:28-31.

8. Kang MJ, Chung CH, Chang YJ, et al. Reconstruction of the lower extremity using free flaps. Arch Plast Surg 2013;40: 575-83.

9. Hattori Y, Chuang DC, Lan CT. Sensory restoration of the skin graft on a free muscle flap: experimental rabbit study. Plast Reconstr Surg 2001;108:132-40.

10. Dayan JH, Lin CH, Wei FC. The versatility of the anterolateral thigh flap in lower extremity reconstruction. Handchir Mikrochir Plast Chir 2009;41:193-202.

11. Shindo ML, Sinha UK, Rice DH. Sensory recovery in noninnervated free flaps for head and neck reconstruction. Laryngoscope 1995;105(12 Pt 1):1290-3.

12. Tremp M, Wettstein R, Raffoul W, et al. Secret scar free gracilis flap.J Reconstr Microsurg 2012;28:341-4.

13. Tremp M, Wang W, Oranges CM, et al. Evaluation of the neo-umbilicus cutaneous sensitivity following abdominoplasty. Aesthetic Plast Surg 2017;41:1382-8.

14. Aherrera AS, Pincus DJ, Vernadakis AJ, et al. Evaluation of abdominal cutaneous sensibility following abdominoplasty. Plast Reconstr Surg 2015;135:526e-532e.

15. Waris T, Rechardt L, Kyosola K. Reinnervation of human skin grafts: a histochemical study. Plast Reconstr Surg
1983;72:439-47.

16. Lee MJ, Yun IS, Rah DK, et al. Lower extremity reconstruction using vastus lateralis myocutaneous flap versus anterolateral thigh fasciocutaneous flap. Arch Plast Surg 2012;39: 367-75.

17. Demirtas Y, Neimetzade T, Kelahmetoglu O, et al. Comparison of free muscle and perforator skin flaps for soft tissue reconstruction of the foot and ankle. Foot Ankle Int 2010;31: 53-8.

18. Chang KN, DeArmond SJ, Buncke HJ Jr. Sensory reinnervation in microsurgical reconstruction of the heel. Plast Reconstr Surg 1986;78:652-64.

19. Gordon L, Buncke HJ, Alpert BS. Free latissimus dorsi muscle flap with split-thickness skin graft cover: a report of 16 cases. Plast Reconstr Surg 1982;70:173-8.

20. Bayramicli M, Jackson IT, Herschman B. Innervation of skin grafts over free muscle flaps. Br J Plast Surg 2000;53:130-6.

21. Lahteenmaki $T$. The regeneration of adrenergic nerves in a free microvascular groin flap in the rat. Scand J Plast Reconstr Surg 1986;20:183-8.

22. Lundborg G, Dahlin LB, Danielsen N, et al. Tissue specificity in nerve regeneration. Scand J Plast Reconstr Surg 1986; 20:279-83. 